\title{
A new junction termination technique: the Deep Trench Termination (DT ${ }^{2}$ )
}

\author{
L. Théolier ${ }^{1,2}$, H. Mahfoz-Kotb ${ }^{3}$, K. Isoird ${ }^{1,2}$, F. Morancho ${ }^{1,2}$ \\ ${ }^{1}$ CNRS ; LAAS \\ 7, avenue du Colonel Roche \\ F-31077 Toulouse, France \\ e-mails: morancho@laas.fr, kisoird@laas.fr \\ ${ }^{2}$ Université de Toulouse \\ UPS, INSA, INP, ISAE ; LAAS \\ F-31077 Toulouse, France \\ ${ }^{3}$ Department of Physics \\ Faculty of Science, Assiut University \\ 71516, Assiut, Egypt \\ e-mail: hesham74@yahoo.com
}

\begin{abstract}
Numerous techniques have been used to improve the voltage handling capability of high voltage power devices with the aim to obtain the breakdown of a plane junction. In this work, a new concept of low cost, low surface and high efficiency junction termination for power devices is presented and experimentally validated. This termination is based on a large and deep trench filled by $\mathrm{BCB}$ (BenzoCycloButene) associated to a field plate. Simulation results show the important impact of trench design and field plate width on termination performances. The experimental breakdown voltage of this Deep Trench Termination $\left(\mathrm{DT}^{2}\right)$ is close to 1300 Volts: this value validates not only the concept of the $\mathrm{DT}^{2}$ but also the choice of the BCB as a good dielectric material for this termination.
\end{abstract}

\section{INTRODUCTION}

The breakdown voltage in high voltage power semiconductor devices is one of the most important problems encountered. In order to improve the breakdown voltage, an adequate edge termination is necessary to reduce the electric field peak at the devices periphery. To date, several techniques have been proposed to reduce this electric field peak: these include guard rings [1], junction termination extension (JTE) [2], field-limiting rings (FLR) [3], field plate (FP) and guard rings [4], field plate and a SIPOS layer [5] and 3D RESURF (Superjunction) [6], [7]. However for high voltage devices, these techniques have the drawback of consuming large area.

Recently, several junction terminations with a deep trench have been reported [8], [9], [10]. The $\mathrm{T}^{3} \mathrm{JTE}$ [8], the concave junction employing deep trench [9] and the deep trench junction termination using inductive coupled plasma reactive ion etching (ICP-RIE) [10] required a deep silicon etching (usually several tens or several hundreds microns) in order to decrease the junction termination area and increase the breakdown voltage. The $\mathrm{T}^{3} \mathrm{JTE}$ was not experimentally demonstrated. The application of the concave termination method is restricted to high voltage devices based on deep junctions such as integrated capacitors on silicon. The deep trench junction termination using ICP RIE is difficult to apply to non-punch through cases.
The purpose of this paper is to report a suitable and relatively low cost junction termination for $1200 \mathrm{~V}$ power devices. This new junction termination, called the Deep Trench Termination $\left(\mathrm{DT}^{2}\right.$ ), is based on the use of dielectric filled, large and deep trench associated to a field plate. Because of the dimensions of this trench termination, conventional thin film deposition techniques were not applicable. As a result, the possibility of trench filling using Spin-On Dielectrics (SOD) was studied. At the end we present experimental results of the $\mathrm{DT}^{2}$ breakdown voltage.

\section{II. $\quad \mathrm{DT}^{2}$ CONCEPT AND THEORETICAL RESULTS}

Fig. 1 shows the cross-sectional view of the proposed DT2 structure. In the proposed device, the trench needs to contain all the potential. For that, termination includes a field plate on top of a dielectric trench.

Fig. 2 shows the 2D-simulated electrostatic potential distribution of the $\mathrm{DT}^{2}$ structure at breakdown. The dielectric in the trench reduces the junction termination area because it sustains all the potential, with a critical electric field higher than that of silicon. In addition, the field plate disables variations of the electrostatic potential in the silicon, guaranteeing a breakdown voltage of the termination near the infinite plane junction breakdown voltage.

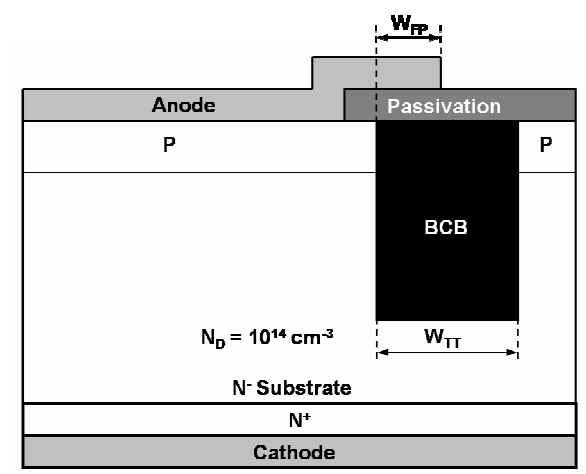

Figure 1. Schematic cross-section of a $\mathrm{PN}^{-}$diode with the Deep Trench Termination $\left(\mathrm{DT}^{2}\right)$. 


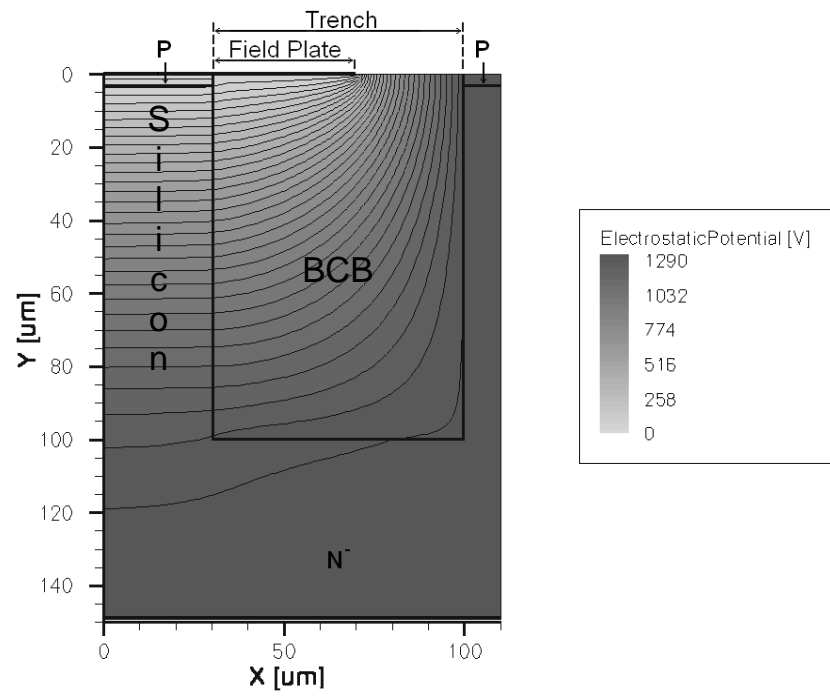

Figure 2. 2D-simulated theoretical potential distribution in the Deep Trench Termination at breakdown.

Fig. 3 shows the 3D-simulated electrostatic potential distribution of the $\mathrm{DT}^{2}$ structure at breakdown. This potential distribution is restricted in the trench like in the 2D simulation. Nevertheless, the 3D-simulated voltage handling capability becomes $80 \%$ of the 2D-simulated voltage handling capability $(1060 \mathrm{~V}$ versus $1290 \mathrm{~V})$. This is due to the cylindrical junction which increases the electric field in the BCB like in the silicon. This result is obtained for a field plate width $\left(\mathrm{W}_{\mathrm{FP}}\right)$ equal to $40 \mu \mathrm{m}$, a trench termination width $\left(\mathrm{W}_{\mathrm{TT}}\right)$ equal to $70 \mu \mathrm{m}$ and an internal radius near $0 \mu \mathrm{m}$. This choice of internal radius was made for Superjunction devices in order to keep the charge balance everywhere in the device. For conventional devices, it is possible to increase this internal radius in order to reach the voltage handling of the plane junction.

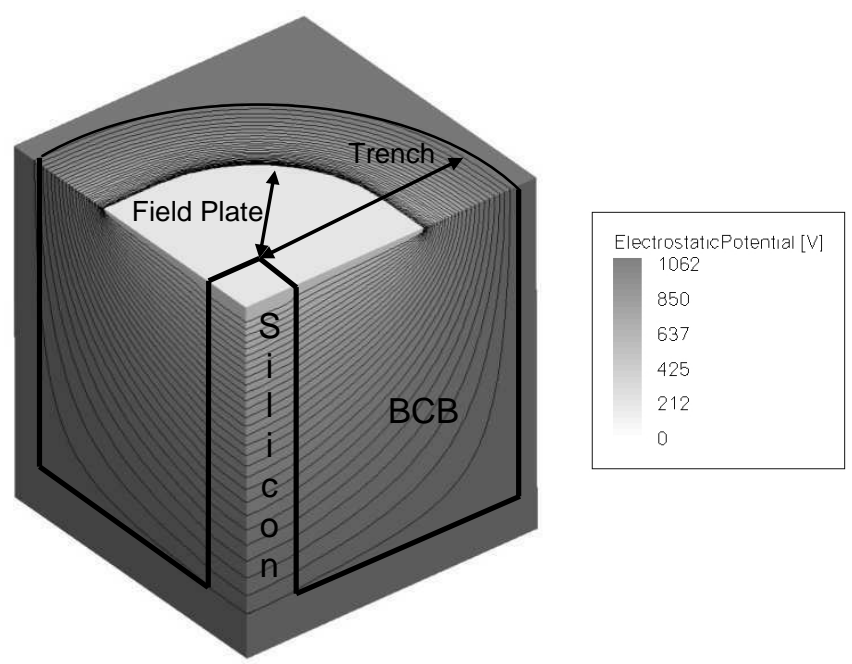

Figure 3. 3D-simulated theoretical potential distribution in the Deep Trench Termination at breakdown.

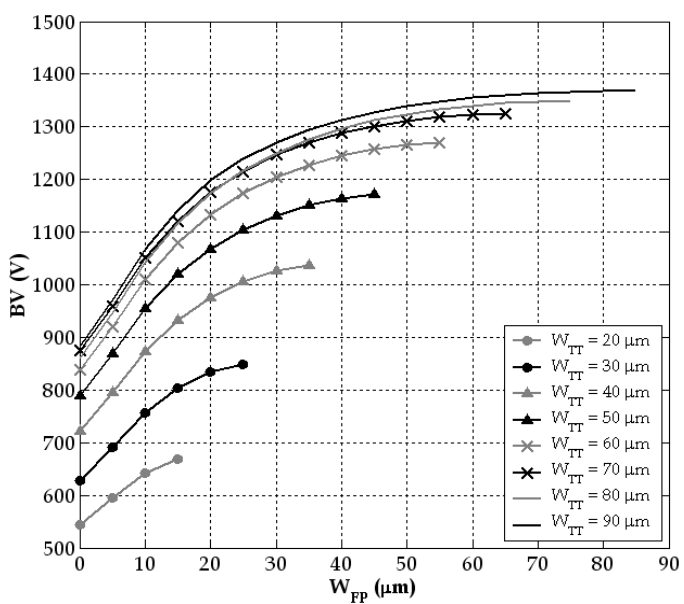

Figure 4. Breakdown voltage variations of the $\mathrm{DT}^{2}$ versus $\mathrm{W}_{\mathrm{FP}}$ and $\mathrm{W}_{\mathrm{TT}}$.

Performances of $\mathrm{DT}^{2}$ depend not only on trench and field plate dimensions but also on dielectrics characteristics of the filling material. Fig. 4 exhibits the breakdown voltage optimization of the $\mathrm{DT}^{2}$ versus the trench termination width $\left(\mathrm{W}_{\mathrm{TT}}\right)$ and the field plate one $\left(\mathrm{W}_{\mathrm{FP}}\right)$ for a 1200 Volts device: in this case, the studied device is a DT-SJMOSFET [11]. The termination without field plate $\left(\mathrm{W}_{\mathrm{FP}}=0\right)$ is not able to sustain more than 900 Volts, even if the trench is very large. In addition, a very low variation of the breakdown voltage can be observed for trench widths higher than $70 \mu \mathrm{m}$. In this case, the breakdown voltage of the trench termination reaches the breakdown voltage of the central cells: if the trench width becomes very important $\left(\mathrm{W}_{\mathrm{TT}}>90 \mu \mathrm{m}\right)$, the termination efficiency is then close to $100 \%$. The optimal couple of values for $\mathrm{W}_{\mathrm{FP}}$ and $\mathrm{W}_{\mathrm{TT}}$, in terms of "performance / size" trade-off, is $40 \mu \mathrm{m}$ and $70 \mu \mathrm{m}$ respectively: with these dimensions, the termination breakdown voltage is equal to $96 \%$ of the base cell one.

Because there are several possibilities of dielectric to fill the deep and wide trench, breakdown voltage of the termination was studied for different types of dielectric, i.e. for different values of critical electric field $\left(\mathrm{E}_{\mathrm{Cd}}\right)$ and permittivity $\left(\varepsilon_{\mathrm{rd}}\right)$. Simulation results on the dependence of the breakdown voltage variations of the $\mathrm{DT}^{2}$ on $\mathrm{E}_{\mathrm{Cd}}$ and $\varepsilon_{\mathrm{rd}}$ are given in Fig. 5. A break can be observed near $2.5 \times 10^{6} \mathrm{~V} . \mathrm{cm}^{-1}$ : below this value of $\mathrm{E}_{\mathrm{Cd}}$, the electric field at the end of the field plate is greater than $\mathrm{E}_{\mathrm{Cd}}$ and the edge cell breaks down before the electric field reaches its critical value in the base cell. For higher values of $\mathrm{E}_{\mathrm{Cd}}$, the base cell breaks down first. This minimal value of $E_{C d}$ is only available for the trench shape of this study (70 $\mu \mathrm{m}$ width). In fact, the maximal electric field in the edge is located at the end of the field plate. Its value depends on the trench width and on the field plate width. In addition, the breakdown voltage of the edge cell is constant for high dielectric permittivities. According to these simulations results, a large variety of dielectric materials is possible to fill the trench termination. 


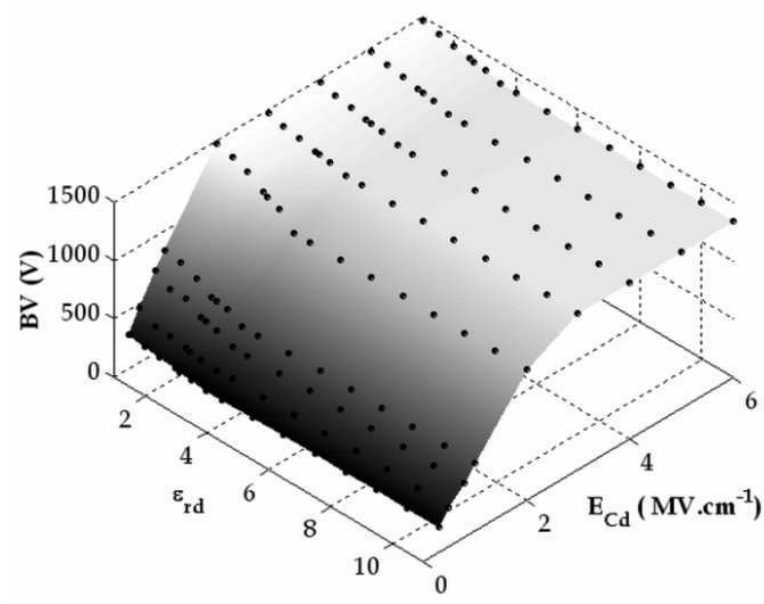

Figure 5. Breakdown voltage variations of the $\mathrm{DT}^{2}$ versus $\mathrm{E}_{\mathrm{Cd}}$ and $\varepsilon_{\mathrm{rd}}$.

TABLE I. SUMMARY OF THE MAIN PROPERTIES OF BCB COMPARED TO $\mathrm{SIO}_{2}$ PROPERTIES (BCB PROPERTIES FROM [12])

\begin{tabular}{|c|c|c|}
\hline Property & $\mathbf{S i O}_{\mathbf{2}}$ & BCB \\
\hline Dielectric constant $(\boldsymbol{\varepsilon})$ & 3.9 & 2.65 \\
\hline Dielectric field strength $(\mathbf{M V / c m})$ & $6-11$ & 5.3 \\
\hline CTE $($ ppm/K) & 0.5 & 42 \\
\hline Glass transition temperature $\left({ }^{\circ} \boldsymbol{C}\right)$ & $>1200$ & $>350$ \\
\hline Residual stress on $\mathbf{S i}(\mathbf{M P a})$ & +100 to +300 & $-28 \pm 2$ (tensile) \\
\hline Index of refraction & 1.46 & 1.54 at $1300-1550 \mathrm{~nm}$ \\
\hline Shrinkage after cure & $\mathrm{n} / \mathrm{a}^{\mathrm{b}}$ & $<5 \%$ \\
\hline${ }^{\mathrm{b}}$ Not available & &
\end{tabular}

A good candidate is the BenzoCycloButene (BCB) polymer. Its good electrical properties are given in Table 1 and compared to those of silicon oxide. Besides BCB is known to have a low moisture uptake $(0.24 \%$ at $85 \% \mathrm{RH})[12,13]$.

\section{EXPERIMENTAL RESULTS}

In order to evaluate the performance of this novel termination, a $\mathrm{PN}^{-}$diode using the proposed $\mathrm{DT}^{2}$ at its periphery (Fig. 1) was fabricated on a N-type substrate with a resistivity and thickness of $50 \Omega . \mathrm{cm}$ and $520 \mu \mathrm{m}$ respectively. This choice of parameters allows avoiding breakdown in the center of the device because the breakdown voltage of the $\mathrm{PN}^{-}$ plane junction should be close to 1400 Volts and breakdown would then occur at the device termination. The trench depth and width are $100 \mu \mathrm{m}$ and $70 \mu \mathrm{m}$ respectively. Because of its high dimensions, the trench has to be realized by Deep Reactive Ion Etching (DRIE). After DRIE etching of silicon substrates to the needed depth, adhesion promoter AP $3000^{\mathrm{TM}}$ (from Dow Chemical) is applied onto the wafer. Then, Cyclotene 4026-46 BCB resin is spun. Afterwards, BCB is hard cured inside a furnace tube in $\mathrm{N}_{2}$ ambient at $250{ }^{\circ} \mathrm{C}$. A temperature ramp of about $1.5{ }^{\circ} \mathrm{C} \cdot \mathrm{min}^{-1}$ was used to arrive at $250{ }^{\circ} \mathrm{C}$. However, for a complete filling of the edge trench, another layer of BCB was necessary. The second layer is applied and cured in the same conditions as previously. After trench filling an excess, uneven BCB layer of about $30 \mu \mathrm{m}$ is formed on the surface of the substrate. To smooth the surface
TABLE II. CMP PARAMETERS

\begin{tabular}{|c|c|}
\hline Slurry & $\begin{array}{c}\text { Klebosol STS-2: } 30(\mathbf{w t} \%) \text { silica abrasives } \\
\text { (grain size }=\mathbf{2 5} \mathbf{~ n m}), \mathbf{p H}=\mathbf{2 . 5}\end{array}$ \\
\hline Slurry flow rate & $50 \mathrm{ml} / \mathrm{min}$ \\
\hline Down force pressure & $2 \mathrm{psi}$ \\
\hline Backside pressure & $2 \mathrm{psi}$ \\
\hline Platen rotation speed & $60 \mathrm{rpm}$ \\
\hline Carrier rotation speed & $50 \mathrm{rpm}$ \\
\hline
\end{tabular}

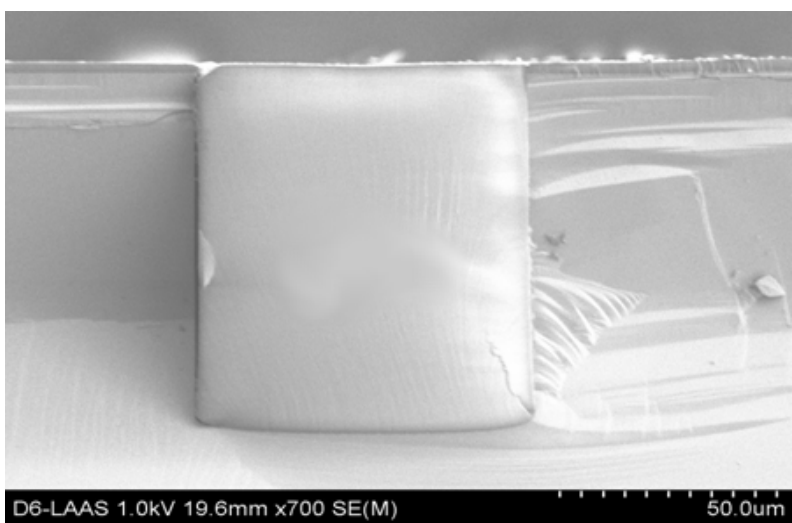

Figure 6. SEM photograph of the BCB-filled trench termination after CMP.

topography of the substrate and remove excess $\mathrm{BCB}$ coating after BCB filling, Chemical Mechanical Polishing (CMP) of $\mathrm{BCB}$ is realized using a Logitech CDP (CMP) system. The parameters for the CMP process are given in Table 2.

These conditions for the CMP process have enabled an etch rate of $\mathrm{BCB}$ of about $0.24 \mu \mathrm{m} / \mathrm{min}( \pm 0.04 \mu \mathrm{m} / \mathrm{min})$. Polishing is stopped before reaching the surface of the silicon substrate (Fig. 6). In this way, a layer of about $500 \mathrm{~nm}$ of BCB is left on the surface to act as a dielectric under the field plate. In average, a polishing time of about 120 min was necessary to prepare the surface of the substrate for next steps. After polishing, openings are realized in BCB by dry etch and metal contacts are deposited. The field plate is made in the same time as metallization. One can notice that the technological process is relatively simple and could be used for the realization of a wide variety of high voltage power devices. The relatively long time of polishing would be reduced by modifying the CMP parameters.

The OFF-state performance of this new structure was electrically verified. Fig. 7 shows the measured and 2D simulated reverse J-V (current density versus voltage) characteristics. The simulation previewed a 1290 Volts breakdown voltage and the measurements exhibit 1310 Volts. These results are very close, showing the good process control of the device. Such performance can be reached thanks to the high critical electric field in the BCB. Furthermore, the measured leakage current of the $\mathrm{DT}^{2}$ is equal to $10 \mu \mathrm{A} / \mathrm{cm}^{2}$ just before breakdown, which is a very acceptable and conventional value. Fig. 8 shows that this is the termination which breaks down: this validates not only the $\mathrm{DT}^{2}$ concept but also the choice of the BCB as a good dielectric material for this termination, in terms of mechanical and electrical properties. 


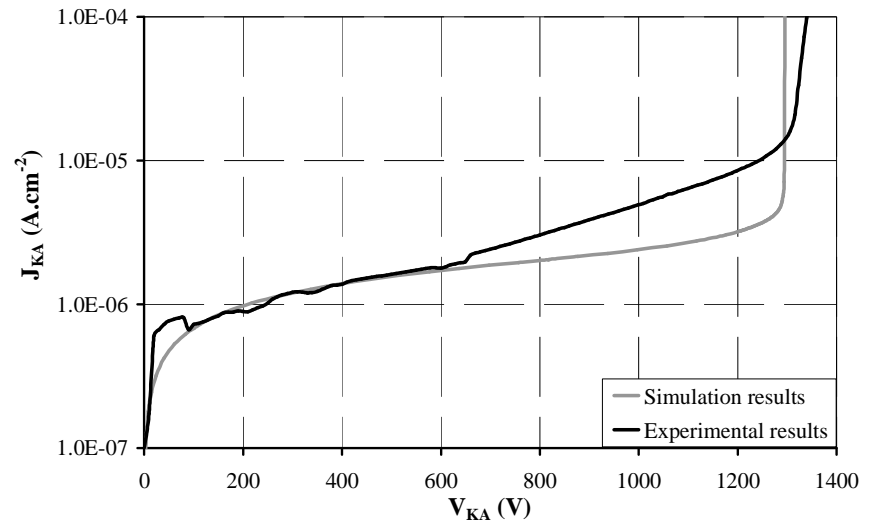

Figure 7. Measured and simulated $\mathrm{J}-\mathrm{V}$ reverse characteristics of a $\mathrm{PN}^{-}$ diode using the proposed $\mathrm{DT}^{2}$ structure.

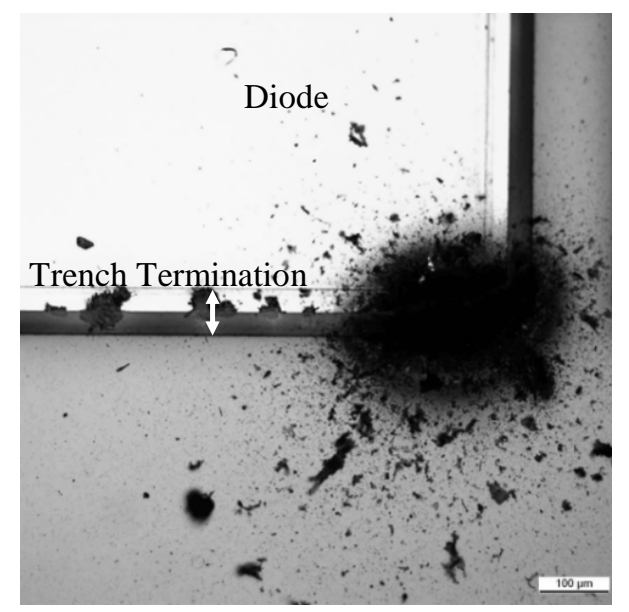

Figure 8. Device damage in the corner of the test diode after breakdown: that confirms that breakdown occurs in the $\mathrm{DT}^{2}$.

\section{CONCLUSION}

A new junction termination for $1200 \mathrm{~V}$ power devices, consisting in a $70 \mu \mathrm{m}$ width and $100 \mu \mathrm{m}$ depth trench filled by a dielectric (the BenzoCycloButene), is proposed for the first time. Simulation results showed that the $\mathrm{DT}^{2}$ exhibits a blocking voltage capability near the ideal breakdown voltage when using a filling material with a critical electric field of at least $2.5 \mathrm{MV} / \mathrm{cm}$. A $\mathrm{PN}^{-}$diode with the $\mathrm{DT}^{2}$ was fabricated; the technological process is relatively simple and could be used for the realization of a wide variety of high voltage power devices. Experimental data show that this new junction termination sustains $1300 \mathrm{~V}$ with a leakage current of $10 \mu \mathrm{A} / \mathrm{cm}^{2}$, like predicted by theory. Furthermore, the width of the $\mathrm{DT}^{2}$ being only $70 \mu \mathrm{m}$, one can notice that the junction termination area is dramatically decreased compared to conventional junction terminations in this voltage range $[6,7]$.

\section{REFERENCES}

[1] Y. C. Kao, E. D. Wolley, "High-Voltage Planar p-n Junction", Proceedings of the IEEE, vol. 55, 1967.

[2] V. A. K. Temple, W. Tantraporn, "Junction termination extension for the near-ideal breakdown voltage in p-n junction", IEEE Trans. Electron Devices, vol. ED-33, pp. 1601-1608, Oct. 1986.

[3] J-K. Oh, M-W. Ha, M-K. Han, Y-I. Choi, "A New Junction Termination Method Employing Shallow Trenches Filled With Oxide", IEEE Trans. Electron Devices, vol. ED-25, pp. 16-18, Jan. 2004.

[4] C. B. Goud, K. N. Bhat, "Two-dimensional analysis and design consideration of high-voltage planar junctions equipped with field plate and guard ring", IEEE Trans. Electron Devices, vol. 38, pp. 14971504, Sept. 1991.

[5] D. Jaume, G. Charitat, J.M. Reynès, P. Rossel, "High voltage planar devices using field plate and semi-resistive layers", IEEE Trans. Electron Devices, vol. 38, pp. 1681-1684, July 1991.

[6] Y. Bai, A. Q. Huang, X. Li, "Junction termination technique for Super Junction devices", Proceedings ISPSD'2000, Toulouse (France), pp. 257-261, May 2000.

[7] Z. Qu, "Termination structure for Superjunction device", US Patent NoUS 6621122, 2003.

[8] D. Dragomirescu, G. Charitat, "Trench Termination Technique with vertical JTE for 6kV Devices", Proceedings of BCTM'00, pp. 86-89, Sept. 2000.

[9] H. Hakim, J-L. Sanchez, J-P. Laur, P. Austin, M. Breil, "The concave junction: an attractive topology to design specific junction terminations", Proceedings of ISPSD’02, pp. 193-196, May 2002.

[10] C. Park, N. Hong, D. J. Kim, K. Lee, "A new junction termination technique using ICP RIE for ideal breakdown voltages", Proceedings of ISPSD'02, pp. 257-260, May 2002.

[11] H. Mahfoz-Kotb, L. Théolier, F. Morancho, K. Isoird, P. Dubreuil, T. Do Conto, "Feasibility study of a junction termination using deep trench isolation technique for the realization of DT-SJMOSFETs", Proceedings of ISPSD’08, pp. 303-306, May 2008.

[12] Dow Chemical Company Processing for CYCLOTENE 4000 Series Photo BCB Resins, February 2005.

[13] D. Burdeaux, P. Townsend, J. Carr, "BenzoCycloButene (BCB) dielectrics for the fabrication of high density, thin film multichip modules", J. of Electronic material, vol. 19, No. 12, pp. 1357-1366, 1990. 